\title{
The enduring and contagious optimism of change makers
}

\author{
Norman E. Taylor*
}

I am fairly certain our readers will appreciate the difficulty of my task here, to introduce a journal issue, likely any journal issue, during the first quarter of 2021. So many of us directed our ever-straining faith towards a good-riddance ending to 2020, even as we still struggled daily to comprehend and adapt to the multi-layered global, national, and local conditions. Maybe a few mixed metaphors might help?

Such was a year in which public health, social equity, and disrupted political currents coalesced into a tsunami, a wave that swamped our systems and our psyches, alike.

Alas, the new year has yet to reveal any silver bullet solutions. In fact, thus far, it appears to have barely paused to reload.

For many of us, the months ahead appear to promise only that daily injections of anxiety still remain more likely than those coveted two-dose injections coming in sufficient number to reduce our vulnerability to infection.

Enough of those? And yet, we persevere.

First responders, front-line health and social workers, and essential workers across a range of industries continue to brave public spaces to keep the world turning for the rest of us. Many of us merely commute between rooms, open a computer screen, and continue to engage through virtual means with colleagues and collaborators, suppliers and customers, teachers and learners. Out in the public spaces we share, the term "eyes-only" has taken on new meaning. But, as our eyes may be fixed by necessity on getting through tough days, we are fortunate that many continue to lift their gaze to a better future.

As I reviewed the diverse slate of authors and their articles curated for this issue by our Editorial Team, I was struck by the common denominator evident in their optimism. Every one of them is showcasing new ways and new possibilities that can help the system bend to better serve society. Some are directly seeking to restore trust where it has eroded or create it where it never was; some, to help build greater strengths and protections for individuals, families, or communities; some, to conceive and deliver more responsive services to those who need them most; and others, to advance the essential re-engineering and modernization of our justice apparatus.

Notably, many of these papers also continue to reinforce both the urgency of and commitment to multi-disciplinary collaboration as essential to bringing these changes about. Just a week after the release of this Issue 6 (1) of our Journal of Community Safety and Well-Being, our journal will again play an active role in the Sixth International Conference on Law Enforcement and Public Health (LEPH2021). The same combined spirit of resilience and optimism already hovers over this upcoming conference. Originally scheduled as another mass gathering of like-minded academics, practitioners, and policy-makers from around the world, situated this time in Philadelphia, PA, the hosts and organizers have admirably executed their pivot to a fully virtual event.

Two papers in this current issue are already keyed to these LEPH proceedings, and the theme of our upcoming June issue will be directly linked to the conference proceedings, with several papers already committed from presenters and panellists who will be participating. We look forward to robust online engagement throughout the week-long event, albeit absent the enjoyable dinners and social gatherings that the City of Philadelphia would have otherwise delivered as a bonus.

In the meantime, we are pleased to offer an excellent suite of reading material, much of it peer-reviewed, some as commentary, and, through our commitment to open access, we invite you to enjoy it all from the safety and comfort of your home. Stay well.

\section{CONFLICT OF INTEREST DISCLOSURES}

The author has continuing business interests that include providing advisory services to communities, police services and related human service agencies.

\section{AUTHOR AFFILIATIONS}

* Editor-in-Chief

Correspondence to: Norman E. Taylor, Community Safety Knowledge Alliance, 120 Sonnenschein Way - Main, Saskatoon, SK S7M OW2, Canada.

E-mail: ntaylor@cskacanada.ca

To cite: Taylor, N. E. (2021). The enduring and contagious optimism of change makers. Journal of Community Safety and Well-Being, 6(1), 1.

https://doi.org/10.35502/icswb. 188

(C) Author(s) 2021. Open Access. This work is distributed under the Creative Commons BY-NC-ND license. For commercial re-use, please contact sales@sgpublishing.ca.

gPUBLISHING Published by SG Publishing Inc. OSAA Official publication of the Community Safety Knowledge Alliance. 